\title{
Psychological, social and biological correlates of body perception disturbance in complex regional pain syndrome
}

\author{
H. Schulte-Goecking ${ }^{1,2,3}$ (D) M. Azqueta-Gavaldon ${ }^{1} \cdot$ C. Storz ${ }^{1} \cdot$ M. Woiczinski ${ }^{1} \cdot$ P. Fraenkel ${ }^{4} \cdot$ J. Leukert ${ }^{1}$. \\ S. C. Azad ${ }^{2,3} \cdot$ E. Kraft ${ }^{1,3}$
}

Published online: 20 February 2020

(C) The Author(s) 2020

\begin{abstract}
Body Perception Disturbance (BPD) in Complex Regional Pain Syndrome (CRPS) still represents a poorly understood phenomenon. Research has shown that knowledge about changes in body perception can yield relevant information for understanding and treating the disease. This study addressed possible connections between BPD and psychological and social factors, pain intensity, and disease duration. Sixty patients with chronic CRPS Type I of the hand were recruited. Body Perception Disturbance was assessed using the Galer and Jensen Neurobehavioral Questionnaire (GJ) and the BATH CRPS Body Perception Disturbance Scale (BATH). Depression, anxiety, stress, childhood trauma and other life events were assessed using standardized and validated questionnaires. This study found that BPD in CRPS was significantly correlated with measures of depression, anxiety, current stress, quality of life, and pain intensity, but not with stress experienced in the twelve months preceding onset of illness, childhood trauma, or duration of illness. Future research needs to identify which patients are most likely to develop these psychological conditions of CRPS, so that early, preventive intervention is possible. This study establishes a relationship between depression, anxiety, current stress, quality of life, pain intensity, and BPD severity. It also supports literature suggesting that preexisting stress, childhood trauma, and disease duration have no influence on BPD. The findings suggest that there is a bidirectional influence between brain alterations, psychological symptoms, and illness severity.
\end{abstract}

Keywords CRPS $\cdot$ Body Perception Disturbance $\cdot$ Depression $\cdot$ Anxiety $\cdot$ Childhood trauma $\cdot$ Pain

\section{Introduction}

The present article reports a study that examined the possible relationship between psychological and social factors - anxiety, depression, current stress, quality of life, childhood trauma, as well as pain - and Body Perception Disturbance (BPD) in Complex Regional Pain Syndrome (CRPS). Complex Regional Pain Syndrome is a painful condition affecting the extremities. It is usually caused by physical trauma and

H. Schulte-Goecking

heike.schultegoecking@med.uni-muenchen.de

1 Department of Orthopedics, Physical Medicine and Rehabilitation, Medical Center of the University of Munich, Munich, Germany

2 Department of Anesthesiology, Medical Center of the University of Munich, Munich, Germany

3 Interdisciplinary Pain Unit, Medical Center of the University of Munich, Munich, Germany

4 Department of Psychology, The City College of New York, New York, NY, USA characterized by severe pain. The intensity of the pain stands in no relation to the initiating incident. Pain, as well as the concomitant motor, sensory and autonomic disturbances, typically extends distally beyond the original area of the injury and does not follow the innervation areas of nerves (Schwartzman et al. 2009). The rate of CRPS is three to four times higher in women than in men (de Mos et al. 2007) and is associated with negative consequences in terms of psychological and social functioning (Lohnberg and Altmaier 2013; Sohn et al. 2016). The connection between chronic pain and adverse psychological (Dersh et al. 2002; Wilson et al. 2002) and social (Gatchel et al. 2007; Turk et al. 2008) effects is well established.

The hypothesis that psychological and social factors influence the development of CRPS has received mixed support. Stressful life events in the year before CRPS onset have been suspected to play an important role; however, results have not been conclusive (Geertzen et al. 1998; Monti et al. 1998). Beerthuizen et al. (2009) conducted a comprehensive review and found no relationship between chronic CRPS and psychological and social factors. The research group then conducted 
a large prospective multicenter study (Beerthuizen et al. 2011) and found that depression, anxiety and other psychological factors, as well as stressful life events, did not predict the development of CRPS in patients suffering a physical trauma. Although such a finding needs to be replicated, it suggests that anxiety, depression, and pre-existing stress are not causative factors for CRPS. Rather, these psychological conditions are likely to be sequelae of CRPS. Studies have shown that chronic pain leads to elevated depression and anxiety (Gore et al. 2012), spatial working memory deficits (Kim et al. 2012), and problems in emotional decision making (Apkarian et al. 2004; Gupta et al. 2009). These results corroborate the idea that instead of serving as predisposing psychological risk factors, psychological abnormalities in CRPS seem to be a consequence of chronic pain and disability and the resulting changes in the brain.

Indeed, studies employing structural and functional magnetic resonance imaging (Barad et al. 2014; Hotta et al. 2017; Maihöfner et al. 2004; Pleger et al. 2014; Shokouhi et al. 2017) and magnetoencephalographic recordings (Buntjen et al. 2017) have shown cortical reorganization of the primary somatosensory cortex, altered grey matter structure, abnormal brain system morphology, and changed neural activities in brain areas dealing with sensorimotor functions, pain perception, and emotional experiencing. The prefrontal cortex is thinner in patients suffering from CRPS than in healthy controls (Lee et al. 2015), resulting in impairment of executive functions (Libon et al. 2010) as well as disinhibited pain perception. These results indicate that psychological and cognitive changes in patients with CRPS are due to physiological alterations in the brain (Schwartzman et al. 2009).

This neuroplasticity is particularly crucial to understanding the change in body perception in CRPS. It is estimated that between $50 \%$ to $80 \%$ of patients with CRPS develop so-called "neglect-like symptoms" (Förderreuther et al. 2004; Galer and Jensen 1999; Lewis et al. 2007), similar to those seen in patients who have had a right-sided stroke (Förderreuther et al. 2004; Frettlöh et al. 2006; Kolb et al. 2012). However, studies have shown that neglect-like symptoms in CRPS are not quite the same as in patients who have had a stroke (Förderreuther et al. 2004; Frettlöh et al. 2006; Kolb et al. 2012). Therefore, the term body perception disturbance (BPD) was introduced (Lewis et al. 2007; Lewis and McCabe 2010). Body perception disturbance encompasses elements of body schema (for example, reduced proprioceptive acuity and mislocalization of tactile stimuli) and body image disturbance (for example, the affected limb is perceived to be larger and not belonging to the body (Moseley et al. 2012; Trojan et al. 2019). Body schema is defined as a "non-conscious system of processes that constantly regulate posture and movement" (Gallagher 1986), and is maintained through tactile, visual and proprioceptive stimuli. The primary (S1) and secondary (S2) somatosensory cortices (Maihöfner et al. 2004; Pleger et al. 2014) as well as the motor cortex (M1) and occipitotemporal cortex (OTC) (Orlov et al. 2010) play an important role in forming and maintaining body schemata.

In turn, body schema influences a person's body image, defined as "a system of sometimes conscious perceptions, attitudes, and beliefs pertaining to one's own body" (Gallagher 1986). Body image is easily manipulated, not only in persons with chronic pain conditions but also in people with no pain or other medical conditions (Giummarra et al. 2008; Lackner 1988; Ramachandran 1998). Because personal beliefs, memories, physical changes, as well as psychosocial factors can have modulating effects, a person's body image is considered unstable. For example, it has been shown that depression and anxiety as well as physical and emotional trauma affect a person's body image (Fang et al. 2015; Levine et al. 2005; Sabik 2017; Sack et al. 2010; Taylor and Pooley 2017). Bean and colleagues (Bean et al. 2015) found that patients with CRPS who had low levels of anxiety and disability at the time of diagnosis also reported the least pain and conversely, those with the highest levels of anxiety had the highest amount of pain. This held true for the twelve months following the diagnosis. Poorer outcome after one year was associated with anxiety and pain-related fear. Depression, anxiety and pain intensity are also predictors of disability in CRPS (Bean et al. 2014). Symptoms of a changed body image are prevalent in other chronic pain conditions although not as severe as in CRPS (Frettlöh et al. 2006; Michal et al. 2017). Studies have shown that pain severity and the degree of felt body image distortion are linked (Senkowski and Heinz 2016; Wittkopf et al. 2018). Punt and colleagues (Punt et al. 2013) argue that due to pain and immobility in CRPS, fear-avoidance behavior develops, resulting in suppression of movement. This so-called "learned nonuse" leads to modifications in the cortical regions representing the diseased body part.

Traumatic childhood experiences are another possible factor influencing the development of CRPS and therefore, BPD. An increasing number of studies support the hypothesis that traumatic experiences in childhood, i.e. sexual, physical and emotional abuse, significantly increase the risk of developing psychological and physical diseases in later life, in particular diseases with inflammatory processes (Burke et al. 2017; Davis et al. 2019; Dube et al. 2009; Felitti 2009; Kraynak et al. 2019; Van Niel et al. 2014). Similar to CRPS, the affected population is predominantly female. Patients with a history of abuse often suffer from body image disturbance, which is also associated with other comorbidities, such as depression, anxiety, borderline personality disorder, and eating disorders (Dyer et al. 2013; Malecki et al. 2018). Therefore, it seems possible that individuals with traumatic experiences may be more likely to develop CRPS.

There is no consistent evidence to determine whether BPD symptoms arise as a direct result of CRPS-induced changes in 
specific brain areas; or if these symptoms occur in response to maladaptive learning (e.g. fear-avoidance behavior); or if BPD is influenced by psychological and social factors (Michal et al. 2017). Based on the literature, the present study sought to examine the possible role of psychological and social factors in BPD.

Based on the research described above, we tested the following three hypotheses:

1. In chronic CRPS Type I of the upper extremity, the severity of body schema disturbance correlates positively with psychological and social factors, including depression, anxiety, current stress, quality of life, traumatic experiences during childhood, stressful life events in the 12 months before onset of the disease;

2. In chronic CRPS Type I of the upper extremity, severity of body schema disturbance correlates positively with pain intensity;

3. In chronic CRPS Type I of the upper extremity, severity of body schema disturbance correlates positively with duration of the disease.

\section{Methods}

\section{Recruitment and subjects}

This cross-sectional study was approved by the research ethics committee of the Ludwig-Maximilian-University of Munich, Germany. Written informed consent was obtained from all participants. Sixty-eight adult patients with chronic (longer than six months) CRPS Type I of the hand were contacted, and sixty (fifty female and ten male subjects) agreed to participate. Recruitment took place in two large outpatient interdisciplinary pain clinics in Germany as well as through two internet-based CRPS self-help network sites (crps-netwerk. org; unfallopfer.de). In order to be included, the patient had to be diagnosed by following the IASP Budapest clinical criteria for the diagnosis of CRPS. The physician who made the CRPS diagnosis submitted written documentation of the diagnosis. Patients were excluded from the study if they had additional, severe medical or psychiatric comorbidities, such as multiple sclerosis, Parkinson's disease, schizophrenia, or any form of personality disorder.

\section{Questionnaires}

Demographic data and pain The German Pain Questionnaire, version 2015, is a 24-item self-report instrument developed by the German Association of Pain (Nagel et al. 2015). It includes demographic questions and assesses all aspects of pain (description, strength, exacerbating and palliative factors, mental model of pain) as well as the development of the disease in question, medications, forms of therapies used, medical and psychiatric comorbidities, the patient's living situation, educational background, and work career.

Current depression, anxiety and stress The German Pain Questionnaire also incorporates a screening instrument for depression, anxiety, and stress, the Depression Anxiety Stress Scales (DASS-21, Nilges and Essau 2015). This 21item self-report questionnaire consists of three subscales, each comprised of 7 items rated on a Likert-type scale (0-3). The range of each subscale is therefore $0-21$. The average Cronbach's alpha coefficient for the DASS depression subscale is reported as 0.91 , for anxiety $0.78-0.82$, and for stress $0.81-0.89$. The German version of the Hospital Anxiety and Depression Scale (HADS-D) is a 14-item self-report questionnaire used to assess depression and anxiety symptoms (Herrmann et al. 1994). Each subscale comprises seven items rated with a Likert-type scale (0-3) with total subscale scores, therefore, ranging from 0 to 21 . The scale has good psychometrics for internal consistency $(\alpha=0.80)$ and test-retest reliability $(r h o=0.80)$.

Past psychological trauma The short version of the Childhood Trauma Questionnaire (CTQ) is a 28-item self-report instrument, which was used to assess childhood maltreatment, including sexual, physical, and emotional abuse, as well as emotional and physical neglect (Bernstein et al. 1994; Spinhoven et al. 2014). Each subscale score is divided into four categories of abuse or neglect: none to low; low to moderate; moderate to severe; severe to extreme. Klinitzke and colleagues used the scale in a representative German sample and found that the subscales had a Cronbach's alpha coefficient above 0.80 . The physical neglect subscale showed high intercorrelations with the other subscales but weak internal consistency (Klinitzke et al. 2012). Klinitzke and colleagues (Kinitzke et al., 2012) hypothesize that this is probably due to some items not being exclusively dependent on the family context, but also on historical circumstances for a certain age cohort. For example, the items stating "when I grew up, I did not have enough to eat" and "when I grew up, I had to wear dirty clothes" describe the reality for large parts of the German population during and following World War II and are not due to physical neglect by caregivers. The authors strongly caution against the application of this subscale in the German population. Therefore, the physical neglect subscale was not used in the present study. The CTQ has high construct validity, as demonstrated by significant positive correlations with measures of anxiety and depression and negative correlations with measures of life satisfaction.

Past stress The Social Readjustment Rating Scale (SRRS), commonly known as the Holmes and Rahe Stress Scale (Rahe 1978; Rahe and Arthur 1978), is a well-known standard 
measure of stress in relationship to illness. This 43-item dichotomous questionnaire asks subjects to indicate the number of stressful events experienced. Each event is assessed in "life change units" and given a different weight. For example, death of a spouse equals 100 points, taking out a bank loan 32 points, change in sleeping habits 16 points. The SRRS has been validated in thousands of people with different cultural backgrounds and was found to be highly reliable, with rank ordering remaining consistent both for healthy adults $(r=$ 0.96-0.89 and patients $r=0.91-0.70$ ) (Gerst et al. 1978). The scale was used to screen for stressful life events within the past year before the onset of CRPS.

Quality of life The Veterans RAND 12-item Health Survey (Kazis et al. 2006) is a widely-used, well-validated measure of health-related quality of life to estimate disease burden. The twelve items are summarized into two scores, a physical health summary measure (PCS-physical component score) and a mental health summary measure (MSC-mental component score). Answers are assigend a score between 0 and 100 . In the statistical analysis they receive another, weighted score (Selim et al. 2009). For both subscales, a higher score denotes better quality of life. The RAND survey is included in the German Pain Questionnaire. The German version is currently being tested, therefore psychometric data are not yet available. However, in earlier versions of the German Pain Questionnaire, the comparable 12-Item Short Form Health Survey (Ware et al. 1996) consisting of 12 questions, and assessing physical (PCS) and mental (MCS) quality of life states, was used successfully $(n=1086$; PCS: $M=30.5$, $S D=8.8$; MCS: $M=44.7, S D=9.4)$.

Body perception disturbance Two scales were used for the assessment of motor and cognitive aspects of BPD. The Galer and Jensen Neurobehavioral Questionnaire (GJ) in the German translation (Frettlöh et al. 2006), is a seven-item Likert-type self-report scale ( $0=$ never to $6=$ always). It comprises two subscales, motor (Items 1, 3 and 4) and cognitive neglect (Items 2 and 5). The scale has excellent internal consistency (Cronbach's alpha $\alpha=0.86$ ) and an effect size of $d=$ 0.57 in distinguishing CRPS patients from normal controls. In the present study, Cronbach's alpha was found to be 0.88 .

The BATH CRPS BPD Scale (Lewis et al. 2007; Lewis and McCabe 2010) was modified and translated into German. This 7-item scale comprises two subscales: cognitive (Items 1, 3, 4, 6, and 7) and motor neglect (Items 2 and 5). Additionally, the BATH scale required the patient to draw their body (Item 7). This drawing was rated by the investigator on a scale from 0 to 2, as follows:

- $0=$ no distortion; the body is drawn anatomically correct, no fingers are missing.
- $1=$ distortion; size or/and form of the hand is anatomically incorrect, but no fingers are missing.

- 2 = severe distortion; size or/and form of the hand is anatomically incorrect, fingers are missing.

In the original study, the questionnaire had an acceptable internal consistency $(\alpha=0.66)$ and excellent inter-rater reliability (Cohen's Kappa $\kappa=0.87$ ). In the present study, alpha was found to be 0.79 .

The GJ and BATH scales were strongly correlated (rho = 0.71 ) in this study, indicating that the two scales measure the same variables. Nevertheless, the statistical analyses utilized the respective individual scores of each scale to measure the severity of BPD.

\section{Statistical analysis}

Data analysis was conducted using IBM SPSS Statistics, Version 24 for Microsoft Windows. Descriptive statistics were used to gain a general overview of the demographic, clinical and psychometric data in terms of means and frequencies. The Shapiro-Wilk test was employed to test for normality of the data. Demographic, clinical and psychometric variables were not normally distributed, with a slight positive skewness; therefore, only nonparametric statistical tests were applied. Spearman's rank-order correlation was used to calculate the strength of association between BPD and all other variables. For variables showing highest correlation with $B P D$, a multiple linear regression analysis was performed to gain a more complete understanding of these associations. Multicollinearity was assessed using Variance Inflation Factor (VIF) tolerances.

For the correlation and regression analyses, the depression and anxiety subscale scores of both the HADS-D and DASS21 questionnaires were combined to form a single depression score and a single anxiety score. Combination of the subscales from different measures has been done elsewhere (Covic et al. 2012; Covic et al. 2009).

\section{Results}

\section{Demographic and pain characteristics}

We recruited 60 patients. The mean age was 57.8 years $( \pm$ 11.82). Twenty-seven patients were affected on the left side, and 33 patients were affected on the right. The average disease duration was 4.5 years $( \pm 3.68)$, and most $(65 \%)$ reported a surgical procedure to be the triggering event for their CRPS. The patients reported a mean pain intensity of 4.4 (based on a Numerical Rating Scale of 0-10). There were no differences 
between female and male participants concerning any of the assessed variables.

\section{Past trauma and stressful life events}

The sample had significantly higher rates of childhood trauma (sexual and physical abuse, emotional neglect) compared to the overall German population (Hauser et al. 2011). Data presented in Table 1 only show severe to extreme abuse/neglect.

Participants had on average low levels of stress twelve months prior to the onset of the disease, as measured by the Social Readjustment Rating Scale $(M=97.1, S D=95.9)$. A score below 150 indicates low levels of stress and a less than $30 \%$ probability of developing a stress-related illness in the next two years.

\section{Current depression, anxiety, and stress}

Based on a clinical cut-off score of 8 , established by Bjelland and colleagues (Bjelland et al. 2002), scores on depression and anxiety as measured by the HADS indicate that $55 \%$ of the subjects met the screening criteria for depression and $52 \%$ met the screening criteria for anxiety. Based on a clinical cutoff score of 10 for depression, 6 for anxiety and 10 for stress, established by the German Pain Questionnaire Handbook (Nagel et al. 2015), scores on depression and anxiety as measured by the DASS indicated that $30 \%$ of the subjects met the screening criteria for depression and $45 \%$ met the screening criteria for anxiety. Moreover, $50 \%$ of the patient showed abnormal levels of stress (Table 2).

\section{Quality of life}

Participants showed a physical component score (PCS) of $33.8(S D=8.2)$ and a mental component score (MCS) of $43.7(S D=14.2)$, indicating no severe deterioration in quality of life (Table 2). However, due to CRPS, 63\% had lost their job and $23 \%$ were in early retirement.

Table 1 Comparison of Past Trauma; Numbers Listed are the Percentages of the Study Participants and General Population Samples, Respectively

\begin{tabular}{lll}
\hline $\begin{array}{l}\text { CTQ Subscales (severe to } \\
\text { extreme abuse/neglect) }\end{array}$ & $\begin{array}{l}\text { Study Participant } \\
(\%) n=60\end{array}$ & $\begin{array}{l}\text { General Population } \\
(\%) n=2504\end{array}$ \\
\hline Sexual abuse & 8.0 & 1.9 \\
Physical abuse & 13.0 & 2.8 \\
Emotional abuse & 2.0 & 1.6 \\
Emotional neglect & 38.0 & 6.6 \\
\hline
\end{tabular}

CTQ Childhood Trauma Questionnaire
Table 2 Means and Standard Deviations for all Scales

\begin{tabular}{llll}
\hline & Range & Mean & \pm SD \\
\hline Depression, HADS & $0-21$ & 7.72 & \pm 4.51 \\
Depression, DASS & $0-21$ & 6.93 & \pm 6.09 \\
Anxiety, HADS & $0-21$ & 7.53 & \pm 4.59 \\
Anxiety, DASS & $0-21$ & 5.16 & \pm 4.08 \\
Stress, DASS & $0-21$ & 9.10 & \pm 5.63 \\
CTQ (total score) & $0-115$ & 38.35 & \pm 13.07 \\
$\quad$ Sexual abuse & $0-25$ & 6.58 & \pm 4.83 \\
$\quad$ Physical abuse & $0-30$ & 9.05 & \pm 3.87 \\
$\quad$ Emotional abuse & $0-25$ & 8.32 & \pm 3.97 \\
$\quad$ Emotional neglect & $0-35$ & 13.73 & \pm 5.92 \\
PCS & $21.1-55.7$ & 33.8 & \pm 8.2 \\
MCS & $12.7-62.9$ & 43.7 & \pm 14.2 \\
SRRS & $0-1467$ & 97.1 & \pm 95.9 \\
Pain & $0-10$ & 4.43 & \pm 2.19 \\
GJ (total score) & $0-30$ & 2.06 & \pm 1.65 \\
$\quad$ GJ cognitive & $0-12$ & 1.80 & \pm 1.70 \\
$\quad$ GJ motor & $0-18$ & 2.35 & \pm 1.87 \\
BATH (total score) & $0-24$ & 2.72 & \pm 1.18 \\
$\quad$ BATH cognitive & $0-18$ & 2.70 & \pm 1.43 \\
$\quad$ BATH motor & $0-6$ & 2.75 & \pm 1.21 \\
\hline
\end{tabular}

$\mathrm{n}=60 ;$ HADS Hospital Anxiety and Depression Scale, DASS Depression, Anxiety and Stress Scale, CTQ Childhood Trauma Questionnaire, PCS Quality of Life - Physical Composite Summary, MCS Quality of LifeMental Composite Summary, SRRS Social Readjustment Rating Scale, GJ Galer and Jensen Neurobehavioral Questionnaire, BATH BATH CRPS Body Perception Disturbance Scale

\section{Body perception disturbance}

Generally, participants exhibited low levels of motor and cognitive levels of neglect (Table 2). The Likert-type scale was divided into two: scores between 0 and 3 meaning low levels, and scores between 4 and 6 meaning higher levels of neglect. For the GJ scale, $62 \%$ of participants had low motor and $78 \%$ had low cognitive neglect. For the BATH scale, $67 \%$ scored low in motor and $88 \%$ low in cognitive neglect. However, the majority of participants drew either a distorted (47\%) or severely distorted (37\%) body image (Fig. 1a and b, respectively).

\section{Correlational and regression analyses}

It was hypothesized that in chronic CRPS of the upper extremity, the severity of BPD would correlate with psychological and social factors (hypothesis 1); pain intensity (hypothesis 2), and duration of disease (hypothesis 3 ). Hypothesis 1 was partially confirmed: BPD showed a strong correlation with depression and anxiety. Stress suffered in the past week was also significantly, but to a lesser extent, correlated with BPD. Both subscales assessing quality of life were significantly correlated 


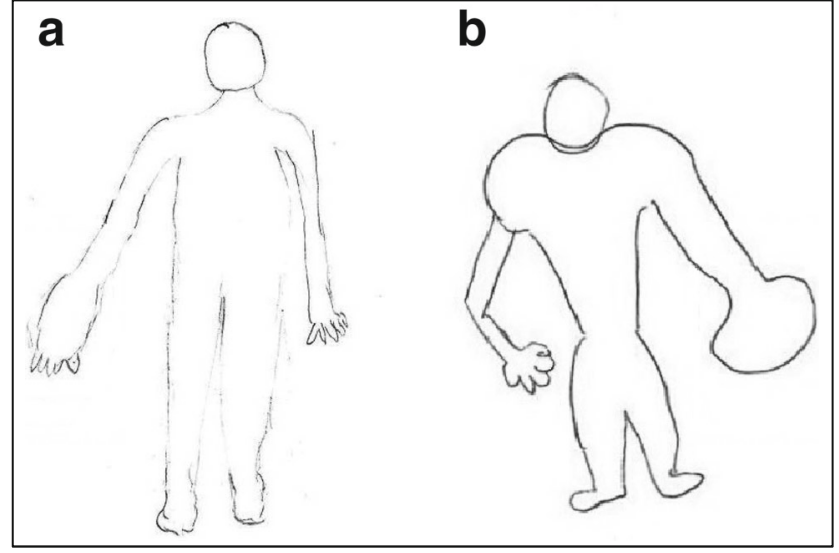

Fig. 1 Example for a Distorted (a) and a Severely Distorted (b) Body Image Drawing

with BPD. Hypothesis 2 was confirmed: Average pain intensity showed a strong correlation with BPD (Table 3).

There was no significant correlation between BPD, disease duration (hypothesis 3), and stress suffered before the developing of CRPS, or with childhood trauma (Table 3). However, one of the four subscales of the CTQ measures emotional neglect and fully $68 \%$ of patients reported emotional neglect at a low $(20 \%)$, medium (10\%) or high (38\%) level. In addition, emotional neglect in childhood correlated with current depression $(r h o(60)=0.29, p<.05)$ and anxiety $(r h o(60)=$ $0.25, p<.05)$.

As will be discussed in the next section, the confirmatory findings are striking because the majority of participants showed neither severe motor nor cognitive neglect as measured with GJ and BATH scales. This suggests that the assessments of both BPD and psychological variables were highly sensitive, because even within a limited range of scores, correlations and regressions were obtained between BPD and several psychological and social variables.

Multiple linear regression analysis was performed to test if anxiety, depression, current stress and pain predicted participants' BPD ratings. In the case of the GJ scale, pain, anxiety and current levels of stress predicted $47 \%$ of the variance. In the case of the BATH scale, two predictors, namely pain and depression explained $44 \%$ of the variance (Table 4 ). The values of tolerance for the independent variables predicting both body perception disturbance scores were higher than
0.3 and, simultaneously, the values of Variance Inflation Factor (VIF) were lower than 3.2. Therefore, it is prudent to assume that no multicollinearity was present in the data.

Another multiple linear regression analysis was utilized to test which variables (BPD, pain, depression, anxiety, stress) influenced quality of life. The physical aspect of quality of life (PCS) was only predicted by pain, which explained $25 \%$ of the variance. The mental aspect of quality of life (MCS) was predicted by depression and stress, which together explained $72 \%$ of the variance (Table 5). The values of tolerance for the independent variables predicting MCS were higher than 0.2 and, simultaneously, the values of Variance Inflation Factor (VIF) were lower than 3.3. Therefore, it is prudent to assume that no multicollinearity was present in the data.

\section{Discussion}

This study found that Body Perception Disturbance (BPD) in Complex Regional Pain Syndrome (CRPS) was significantly correlated with measures of depression, anxiety, current stress, quality of life, and pain intensity, but not with stress experienced in the twelve months preceding onset of illness, childhood trauma, or duration of illness. As was noted earlier, in their prospective multicenter study, Beerthuizen and colleagues (Beerthuizen et al. 2011) found that depression, anxiety and other psychological factors, as well as stressful life events, did not predict the development of CRPS in patients suffering a physical trauma. These psychological conditions are therefore likely to be sequelae of CRPS. Instead of serving as predisposing psychological risk factors, psychological abnormalities in CRPS seem to be a consequence of chronic pain and disability and the resulting changes in the brain. However, it should not be assumed that the directionality of physical brain changes to psychological symptoms is one way, with brain alterations resulting in depression, anxiety and stress. Psychological symptoms may also cause changes in the brain (Mah et al. 2016; Yaribeygi et al. 2017). For example, in a recent review (Sheng et al. 2017) concerning the link between chronic pain and depression, the authors conclude that research clearly shows the close connections between painand depression-induced neuroplasticity as well as changes in neurobiological mechanisms. Psychological symptoms

Table 3 Correlations between Body Perception Disturbance, Pain, Disease Duration, Psychological and Social Variables

\begin{tabular}{|c|c|c|c|c|c|c|c|c|c|}
\hline BPD Scales & Pain & Depression & Anxiety & Stress & PCS & MCS & Trauma & SRRS & DD \\
\hline GJ & $0.538 * *$ & $0.508 * *$ & $0.593 * *$ & $0.374 * *$ & $-0.367 * *$ & $-0.387 * *$ & 0.141 & 0.096 & 0.023 \\
\hline BATH & $0.541 * *$ & $0.619 * *$ & $0.589 * *$ & $0.467 * *$ & $-0.381 * *$ & $-0.501 * *$ & 0.104 & 0.032 & 0.015 \\
\hline
\end{tabular}

**= $p<0.01$ (two-tailed), Spearman; $\mathrm{n}=60 ; B P D$ Body Perception Disturbance, GJ Galer and Jensen Neurobehavioral Questionnaire, BATH BATH CRPS Body Perception Disturbance Scale, PCS Quality of life - Physical Composite Summary, MCS Quality of life - Mental Composite Summary, SRRS Social Readjustment Rating Scale, $D D$ Disease Duration 
Table 4 Summary of Multiple Linear Regression Analysis for Variables Predicting Body Perception Disturbance Ratings

\begin{tabular}{|c|c|c|c|c|c|c|c|c|c|c|}
\hline & \multicolumn{3}{|c|}{ Model Summary } & \multicolumn{5}{|c|}{ Model Variables Coefficients } & \multicolumn{2}{|c|}{ Multicollinearity Diagnostics } \\
\hline & $\mathrm{R}^{2}$ & $\mathrm{~F}$ & $\mathrm{p}$ & $\mathrm{B}$ & SE & $\beta$ & $\mathrm{t}$ & $\mathrm{p}$ & Tolerance & VIF \\
\hline GJ & 0.466 & (3.56) 16.26 & $<.001$ & & & & & & & \\
\hline Pain & & & & 3.11 & 0.102 & 0.361 & 3.814 & $<0.001$ & 0.683 & 1.464 \\
\hline Anxiety & & & & 0.269 & 0.070 & 0.664 & 3.814 & 0.003 & 0.315 & 3.179 \\
\hline Current Stress & & & & -0.099 & 0.49 & -0.340 & -2.034 & 0.047 & 0.341 & 2.931 \\
\hline BATH & 0.437 & (2.57) 22.128 & $<.001$ & & & & & & & \\
\hline Pain & & & & 0.177 & 0.076 & 0.286 & 2.330 & 0.023 & 0.656 & 1.525 \\
\hline Depression & & & & 0.107 & 0.029 & 0.451 & 3.579 & 0.001 & 0.656 & 1.525 \\
\hline
\end{tabular}

GJ Galer and Jensen Neurobehavioral Questionnaire, BATH BATH CRPS Body Perception Disturbance Scale, $\mathrm{n}=60, B$ Unstandardized Regression Weights, $S E$ Standard Error, $\beta$ Standardized Regression Weights, VIF Variance Inflation Factor

interact with the physical illness, and with alterations in the brain, in a reciprocal, bidirectional manner, such that depression, anxiety, and stress may increase the severity of BPD and the intensity of pain and disability associated with CRPS, as well as alterations in brain activity and cortical mass, which then may amplify depression, anxiety, and stress in a vicious spiral, thereby diminishing experienced quality of life. The finding that the majority of patients had experienced emotional neglect may provide a partial explanation for BPD. Emotional neglect in childhood is often associated with, and believed to cause, insecure attachment (Benamer and White 2008). Insecure attachment is highly associated with emotion dysregulation, because children in an insecure relationship with their parents typically do not receive adequate soothing, leading to incapacity to self-soothe both as a child, and as an adult. The inability to self-soothe may then result in increased distress, such as catastrophizing thoughts, about CRPS, leading to worsened BPD.

These findings strongly suggest that psychological and social variables must be incorporated into a comprehensive understanding of the nature of BPD in CRPS. Of course, correlation does not establish causation, and the directionality of the relationship between these variables and the illness cannot be established without further prospective, longitudinal research.

From a methodological perspective, the present study demonstrated the usefulness of including two measures of BPD the GJ and the BATH scales, the latter being a new scale with a particularly interesting behavioral assessment element - having patients draw their afflicted limb. As they were highly correlated, using two scales also added important convergent validity.

Future research needs to identify which patients are likely to have these psychological conditions triggered by CRPS, so that early, preventive intervention is possible. Through such intervention, BPD might be avoided or ameliorated, resulting in improved quality of life.

\section{Limitations of the present study}

The sample was not randomly selected, opening it up to the possibility of unknown selection biases.

The majority of participants showed neither severe motor nor clinical neglect as measured with GJ and BATH scales.

Table 5 Summary of Multiple Linear Regression Analysis for Variables Predicting Quality of Life

\begin{tabular}{|c|c|c|c|c|c|c|c|c|c|c|}
\hline & \multicolumn{3}{|c|}{ Model Summary } & \multicolumn{5}{|c|}{ Model Variables Coefficients } & \multicolumn{2}{|c|}{ Multicollinearity Diagnostics } \\
\hline & $\mathrm{R}^{2}$ & $\mathrm{~F}$ & $\mathrm{p}$ & $\mathrm{B}$ & SE & $\beta$ & $\mathrm{t}$ & $\mathrm{p}$ & Tolerance & VIF \\
\hline PCS & 0.251 & (1.58) 19.36 & $<.001$ & & & & & & & \\
\hline Pain & & & & -2.161 & 0.491 & -0.501 & -4.404 & $<0.001$ & 1.000 & 1.000 \\
\hline MCS & 0.723 & (2.57) 74.55 & $<.001$ & & & & & & & \\
\hline Depression & & & & -1.618 & 0.362 & -0.571 & -4.467 & $<0.001$ & 0.297 & 3.362 \\
\hline Current Stress & & & & -0.788 & 0.321 & -0.313 & -2.453 & 0.017 & 0.297 & 3.362 \\
\hline
\end{tabular}

PCS Quality of Life - Physical Composite Summary, MCS Quality of Life - Mental Composite Summary, $\mathrm{n}=60, B$ Unstandardized Regression Weights, $S E$ Standard Error, $\beta$ Standardized Regression Weights, VIF Variance Inflation Factor 
Although, as noted earlier, this suggests that the assessments of both BPD and psychological variables were highly sensitive, it would be preferable in a next study to recruit a sample with a wider range of motor and cognitive neglect. In retrospect, it might have been a limitation to eliminate patients with psychiatric disorders, since they are most likely to report higher levels of psychological distress surrounding BPD and CRPS. This would likely increase the already strong correlations obtained, and also result in a normal distribution, avoiding the problems encountered in the present study due to a non-parametric data set.

This was a cross-sectional study; as noted above, in order to better assess the potentially causative role of psychosocial variables on BPD, a prospective, longitudinal design would be necessary. However, it is always recommended that, as was done in the present study, cross-sectional studies be performed prior to expensive, complicated prospective studies.

\section{Clinical implications}

The present study suggests that comprehensive treatment of CRPS and BPD associated with CRPS must address patients' risk for the depression, anxiety, and stress associated with it. Recovery from CRPS likely requires treatment of these associated psychological conditions. The possible relationship between a history of childhood emotional neglect and BPD also strongly suggests the need for trauma-based, attachmentbased psychotherapy.

Funding sources Open Access funding provided by Projekt DEAL.

Author contributions H. Schulte-Goecking: Takes responsibility for the integrity of the work as a whole, from inception to publication.

M. Azqueta-Gavaldon: Substantial contribution to analysis and interpretation of data, revising for important intellectual content.

C. Storz: Contribution to acquisition of data.

M. Woiczinski: Contribution to analysis of data.

P. Fraenkel: Substantial contribution in the writing and revising for important intellectual content.

J. Leukert: Contribution to acquisition of data.

S. C. Azad: Final approval of the version to be published.

E. Kraft: Substantial contribution to design of study, final approval of the version to be published.

\section{Compliance with ethical standards}

Ethical approval All procedures performed on the human participants of the study were in accordance with the ethical standards of the institutional and/or national research committee and with the 1964 Helsinki declaration and its later amendments or comparable ethical standards.

Disclosure of potential conflicts of interest The authors declare that they have no conflict of interest.

Informed consent Informed written consent was obtained from all individual participants included in the study.
Open Access This article is licensed under a Creative Commons Attribution 4.0 International License, which permits use, sharing, adaptation, distribution and reproduction in any medium or format, as long as you give appropriate credit to the original author(s) and the source, provide a link to the Creative Commons licence, and indicate if changes were made. The images or other third party material in this article are included in the article's Creative Commons licence, unless indicated otherwise in a credit line to the material. If material is not included in the article's Creative Commons licence and your intended use is not permitted by statutory regulation or exceeds the permitted use, you will need to obtain permission directly from the copyright holder. To view a copy of this licence, visit http://creativecommons.org/licenses/by/4.0/.

\section{References}

Apkarian, A. V., Sosa, Y., Sonty, S., Levy, R. M., Harden, R. N., Parrish, T. B., \& Gitelman, D. R. (2004). Chronic back pain is associated with decreased prefrontal and thalamic gray matter density. Journal of Neuroscience, 24(46), 10410-10415. https://doi.org/10.1523/ jneurosci.2541-04.2004.

Barad, M. J., Ueno, T., Younger, J., Chatterjee, N., \& Mackey, S. (2014). Complex regional pain syndrome is associated with structural abnormalities in pain-related regions of the human brain. The Journal of Pain, 15(2), 197-203. https://doi.org/10.1016/j.jpain.2013.10. 011.

Bean, D. J., Johnson, M. H., Heiss-Dunlop, W., Lee, A. C., \& Kydd, R. R. (2015). Do psychological factors influence recovery from complex regional pain syndrome type 1? A prospective study. Pain, 156(11), 2310-2318. https://doi.org/10.1097/j.pain.0000000000000282.

Bean, D. J., Johnson, M. H., \& Kydd, R. R. (2014). Relationships between psychological factors, pain, and disability in complex regional pain syndrome and low back pain. Clinical Journal of Pain, 30(8), 647-653. https://doi.org/10.1097/ajp.0000000000000007.

Beerthuizen A, van 't Spijker A, Huygen FJ, Klein J, de Wit R. (2009). Is there an association between psychological factors and the Complex Regional Pain Syndrome type 1 (CRPS1) in adults? A systematic review. Pain, 145(1-2), 52-9. https://doi.org/10.1016/j.pain.2009. 05.003 .

Beerthuizen, A., Stronks, D. L., Huygen, F. J., Passchier, J., Klein, J., \& Spijker, A. V. (2011). The association between psychological factors and the development of complex regional pain syndrome type 1 (CRPS1)-a prospective multicenter study. European Journal of Pain (London, England), 15(9), 971-975. https://doi.org/10.1016/ j.ejpain.2011.02.008.

Benamer, S., \& White, K. (Eds.). (2008). Trauma and attachment. London: Karnac Books.

Bernstein, D. P., Fink, L., Handelsman, L., Foote, J., Lovejoy, M., Wenzel, K., Sapareto, E., et al. (1994). Initial reliability and validity of a new retrospective measure of child abuse and neglect. American Journal of Psychiatry, 151(8), 1132-1136. https://doi.org/10.1176/ ajp.151.8.1132.

Bjelland, I., Dahl, A. A., Haug, T. T., \& Neckelmann, D. (2002). The validity of the hospital anxiety and depression scale. An updated literature review. Journal of Psychosomatic Research, 52(2), 69-77.

Buntjen, L., Hopf, J. M., Merkel, C., Voges, J., Knape, S., Heinze, H. J., \& Schoenfeld, M. A. (2017). Somatosensory misrepresentation associated with chronic pain: Spatiotemporal correlates of sensory perception in a patient following a complex regional pain syndrome spread. Frontiers in Neurology, 8, 142. https://doi.org/10.3389/ fneur.2017.00142. 
Burke, N. N., Finn, D. P., McGuire, B. E., \& Roche, M. (2017). Psychological stress in early life as a predisposing factor for the development of chronic pain: Clinical and preclinical evidence and neurobiological mechanisms. Journal of Neuroscience Research, 95(6), 1257-1270. https://doi.org/10.1002/jnr.23802.

Covic, T., Cumming, S. R., Pallant, J. F., Manolios, N., Emery, P., Conaghan, P. G., \& Tennant, A. (2012). Depression and anxiety in patients with rheumatoid arthritis: Prevalence rates based on a comparison of the depression, anxiety and stress scale (DASS) and the hospital, anxiety and depression scale (HADS). BMC Psychiatry, 12, 6. https://doi.org/10.1186/1471-244x-12-6.

Covic, T., Pallant, J. F., Tennant, A., Cox, S., Emery, P., \& Conaghan, P. G. (2009). Variability in depression prevalence in early rheumatoid arthritis: a comparison of the CES-D and HAD-D scales. BMC Musculoskeletal Disorders, 10, 18. https://doi.org/10.1186/14712474-10-18.

Davis, M. C., Lemery-Chalfant, K., Yeung, E. W., Luecken, L. J., Zautra, A. J., \& Irwin, M. R. (2019). Interleukin-6 and depressive mood symptoms: Mediators of the association between childhood abuse and cognitive performance in middle-aged adults. Annals of Behavioral Medicine, 53(1), 29-38. https://doi.org/10.1093/abm/ kay014.

de Mos, M., de Bruijn, A. G., Huygen, F. J., Dieleman, J. P., Stricker, B. H., \& Sturkenboom, M. C. (2007). The incidence of complex regional pain syndrome: a population-based study. Pain, 129(1-2), 12-20. https://doi.org/10.1016/j.pain.2006.09.008.

Dersh, J., Polatin, P. B., \& Gatchel, R. J. (2002). Chronic pain and psychopathology: Research findings and theoretical considerations. Psychosomatic Medicine, 64(5), 773-786.

Dube, S. R., Fairweather, D., Pearson, W. S., Felitti, V. J., Anda, R. F., \& Croft, J. B. (2009). Cumulative childhood stress and autoimmune diseases in adults. Psychosomatic Medicine, 71(2), 243-250. https:// doi.org/10.1097/PSY.0b013e3181907888.

Dyer, A., Borgmann, E., Kleindienst, N., Feldmann Jr., R. E., Vocks, S., \& Bohus, M. (2013). Body image in patients with posttraumatic stress disorder after childhood sexual abuse and co-occurring eating disorder. Psychopathology, 46(3), 186-191. https://doi.org/10.1159/ 000341590 .

Fang, S. Y., Chang, H. T., \& Shu, B. C. (2015). The moderating effect of perceived partner empathy on body image and depression among breast cancer survivors. Psycho-Oncology, 24(12), 1815-1822. https://doi.org/10.1002/pon.3868.

Felitti, V. J. (2009). Adverse childhood experiences and adult health. Academic Pediatrics, 9(3), 131-132. https://doi.org/10.1016/j. acap.2009.03.001.

Förderreuther, S., Sailer, U., \& Straube, A. (2004). Impaired selfperception of the hand in complex regional pain syndrome (CRPS). Pain, 110(3), 756-761. https://doi.org/10.1016/j.pain. 2004.05.019.

Frettlöh, J., Huppe, M., \& Maier, C. (2006). Severity and specificity of neglect-like symptoms in patients with complex regional pain syndrome (CRPS) compared to chronic limb pain of other origins. Pain, 124(1-2), 184-189. https://doi.org/10.1016/j.pain.2006.04.010.

Galer, B. S., \& Jensen, M. (1999). Neglect-like symptoms in complex regional pain syndrome: Results of a self-administered survey. Journal of Pain and Symptom Management, 18(3), 213-217.

Gallagher, S. (1986). Body image and body Schema: A conceptual clarification. The Jourmal of Mind and Behavior, 7(4), 541-554.

Gatchel, R. J., Peng, Y. B., Peters, M. L., Fuchs, P. N., \& Turk, D. C. (2007). The biopsychosocial approach to chronic pain: Scientific advances and future directions. Psychological Bulletin, 133(4), 581-624. https://doi.org/10.1037/0033-2909.133.4.581.

Geertzen, J. H., Dijkstra, P. U., van Sonderen, E. L., Groothoff, J. W., ten Duis, H. J., \& Eisma, W. H. (1998). Relationship between impairments, disability and handicap in reflex sympathetic dystrophy patients: a long-term follow-up study. Clinical Rehabilitation, 12(5), 402-412.

Gerst, M. S., Grant, I., Yager, J., \& Sweetwood, H. (1978). The reliability of the social readjustment rating scale: Moderate and long-term stability. Journal of Psychosomatic Research, 22(6), 519-523.

Giummarra, M. J., Gibson, S. J., Georgiou-Karistianis, N., \& Bradshaw, J. L. (2008). Mechanisms underlying embodiment, disembodiment and loss of embodiment. Neuroscience \& Biobehavioral Reviews, 32(1), 143-160. https://doi.org/10.1016/j.neubiorev.2007.07.001.

Gore, M., Sadosky, A., Stacey, B. R., Tai, K. S., \& Leslie, D. (2012). The burden of chronic low back pain: clinical comorbidities, treatment patterns, and health care costs in usual care settings. Spine, 37(11), E668-E677. https://doi.org/10.1097/BRS.0b013e318241e5de.

Gupta, R., Duff, M. C., Denburg, N. L., Cohen, N. J., Bechara, A., \& Tranel, D. (2009). Declarative memory is critical for sustained advantageous complex decision-making. Neuropsychologia, 47(7), 1686-1693. https://doi.org/10.1016/j.neuropsychologia.2009.02. 007.

Hauser, W., Schmutzer, G., Brahler, E., \& Glaesmer, H. (2011). Maltreatment in childhood and adolescence: Results from a survey of a representative sample of the German population. Deutsches Aerzteblatt International, 108(17), 287-294. https://doi.org/10. 3238/arztebl.2011.0287.

Herrmann, C., Buss, U., Lingen, R., \& Kreuzer, H. (1994). The screening for anxiety and depression in routine medical care. Deutsche Medizinische Wochenschrift, 119(38), 1283-1286. https://doi.org/ 10.1055/s-2008-1058834.

Hotta, J., Saari, J., Koskinen, M., Hlushchuk, Y., Forss, N., \& Hari, R. (2017). Abnormal brain responses to action observation in complex regional pain syndrome. The Journal of Pain, 18(3), 255-265. https://doi.org/10.1016/j.jpain.2016.10.017.

Kazis, L. E., Selim, A., Rogers, W., Ren, X. S., Lee, A., \& Miller, D. R. (2006). Dissemination of methods and results from the veterans health study: final comments and implications for future monitoring strategies within and outside the veterans healthcare system. Journal of Ambulatory Care Management, 29(4), 310-319.

Kim, S. H., Kim, S. H., Kim, S. K., Nam, E. J., Han, S. W., \& Lee, S. J. (2012). Spatial versus verbal memory impairments in patients with fibromyalgia. Rheumatology International, 32(5), 1135-1142. https://doi.org/10.1007/s00296-010-1762-1.

Klinitzke, G., Romppel, M., Hauser, W., Brahler, E., \& Glaesmer, H. (2012). The German version of the childhood trauma questionnaire (CTQ): Psychometric characteristics in a representative sample of the general population. Psychotherapie, Psychosomatik, Medizinische Psychologie, 62(2), 47-51. https://doi.org/10.1055/s0031-1295495.

Kolb, L., Lang, C., Seifert, F., \& Maihofner, C. (2012). Cognitive correlates of "neglect-like syndrome" in patients with complex regional pain syndrome. Pain, 153(5), 1063-1073. https://doi.org/10.1016/j. pain.2012.02.014.

Kraynak, T. E., Marsland, A. L., Hanson, J. L., \& Gianaros, P. J. (2019). Retrospectively reported childhood physical abuse, systemic inflammation, and resting corticolimbic connectivity in midlife adults. Brain, Behavior, and Immunity. https://doi.org/10.1016/j.bbi.2019. 08.186 .

Lackner, J. R. (1988). Some proprioceptive influences on the perceptual representation of body shape and orientation. Brain, 111(Pt 2), 281297.

Lee, D. H., Lee, K. J., Cho, K. I., Noh, E. C., Jang, J. H., Kim, Y. C., \& Kang, D. H. (2015). Brain alterations and neurocognitive dysfunction in patients with complex regional pain syndrome. The Journal of Pain, 16(6), 580-586. https://doi.org/10.1016/j.jpain.2015.03. 006.

Levine, E., Degutis, L., Pruzinsky, T., Shin, J., \& Persing, J. A. (2005). Quality of life and facial trauma: Psychological and body image effects. Annals of Plastic Surgery, 54(5), 502-510. 
Lewis, J. S., Kersten, P., McCabe, C. S., McPherson, K. M., \& Blake, D. R. (2007). Body perception disturbance: a contribution to pain in complex regional pain syndrome (CRPS). Pain, 133(1-3), 111-119. https://doi.org/10.1016/j.pain.2007.03.013.

Lewis, J. S., \& McCabe, C. S. (2010). Body perception disturbance. Practical Pain Management, 60-66.

Libon, D. J., Schwartzman, R. J., Eppig, J., Wambach, D., Brahin, E., Peterlin, B. L., Alexander, G., et al. (2010). Neuropsychological deficits associated with complex regional pain syndrome. Journal of the International Neuropsychological Society, 16(3), 566-573. https://doi.org/10.1017/s1355617710000214.

Lohnberg, J. A., \& Altmaier, E. M. (2013). A review of psychosocial factors in complex regional pain syndrome. Journal of Clinical Psychology in Medical Settings, 20(2), 247-254. https://doi.org/ 10.1007/s10880-012-9322-3.

Mah, L., Szabuniewicz, C., \& Fiocco, A. J. (2016). Can anxiety damage the brain? Current Opinion in Psychiatry, 29(1), 56-63. https://doi. org/10.1097/yco.0000000000000223.

Maihöfner, C., Handwerker, H. O., Neundorfer, B., \& Birklein, F. (2004). Cortical reorganization during recovery from complex regional pain syndrome. Neurology, 63(4), 693-701.

Malecki, J., Rhodes, P., \& Ussher, J. (2018). Childhood trauma and anorexia nervosa: from body image to embodiment. Health Care for Women International, 1-16. https://doi.org/10.1080/07399332. 2018.1492268.

Michal, M., Adler, J., Reiner, I., Wermke, A., Ackermann, T., Schlereth, T., \& Birklein, F. (2017). Association of Neglect-like Symptoms with anxiety, somatization, and depersonalization in complex regional pain syndrome. Pain Medicine, 18(4), 764-772. https://doi. org $/ 10.1093 / \mathrm{pm} / \mathrm{pnw} 214$.

Monti, D. A., Herring, C. L., Schwartzman, R. J., \& Marchese, M. (1998). Personality assessment of patients with complex regional pain syndrome type I. Clinical Journal of Pain, 14(4), 295-302.

Moseley, G. L., Gallace, A., \& Spence, C. (2012). Bodily illusions in health and disease: Physiological and clinical perspectives and the concept of a cortical 'body matrix'. Neuroscience \& Biobehavioral Reviews, 36(1), 34-46. https://doi.org/10.1016/j.neubiorev.2011.03. 013.

Nagel, B., Pfingsten, M., Lindena, G., \& Kohlmann, T. (2015). Deutscher Schmerz-Fragebogen Handbuch. Berlin: Deutsche Schmerzgesellschaft e.V.

Nilges, P., \& Essau, C. (2015). Depression, anxiety and stress scales: DASS-A screening procedure not only for pain patients. Schmerz, 29(6), 649-657. https://doi.org/10.1007/s00482-015-0019-z.

Orlov, T., Makin, T. R., \& Zohary, E. (2010). Topographic representation of the human body in the occipitotemporal cortex. Neuron, 68(3), 586-600. https://doi.org/10.1016/j.neuron.2010.09.032.

Pleger, B., Draganski, B., Schwenkreis, P., Lenz, M., Nicolas, V., Maier, C., \& Tegenthoff, M. (2014). Complex regional pain syndrome type I affects brain structure in prefrontal and motor cortex. PLoS One, 9(1), e85372. https://doi.org/10.1371/journal.pone.0085372.

Punt, T. D., Riddoch, M. J., \& Humphreys, G. W. (2013). Motor extinction: a deficit of attention or intention? Frontiers in Human Neuroscience, 7, 644. https://doi.org/10.3389/fnhum.2013.00644.

Rahe, R. H. (1978). Life change measurement clarification. Psychosomatic Medicine, 40(2), 95-98.

Rahe, R. H., \& Arthur, R. J. (1978). Life change and illness studies: Past history and future directions. Journal of Human Stress, 4(1), 3-15. https://doi.org/10.1080/0097840x.1978.9934972.

Ramachandran, V. S. (1998). Consciousness and body image: essons from phantom limbs, Capgras syndrome and pain asymbolia. Philosophical Transactions of the Royal Society of London. Series B: Biological Sciences, 353(1377), 1851-1859. https://doi.org/10. 1098/rstb.1998.0337.
Sabik, N. J. (2017). Is social engagement linked to body image and depression among aging women? Journal of Women \& Aging, 29(5), 405-416. https://doi.org/10.1080/08952841.2016.1213106.

Sack, M., Boroske-Leiner, K., \& Lahmann, C. (2010). Association of nonsexual and sexual traumatizations with body image and psychosomatic symptoms in psychosomatic outpatients. General Hospital Psychiatry, 32(3), 315-320. https://doi.org/10.1016/j. genhosppsych.2010.01.002.

Schwartzman, R. J., Erwin, K. L., \& Alexander, G. M. (2009). The natural history of complex regional pain syndrome. Clinical Journal of Pain, 25(4), 273-280. https://doi.org/10.1097/AJP. 0b013e31818ecea5.

Selim, A. J., Rogers, W., Fleishman, J. A., Qian, S. X., Fincke, B. G., Rothendler, J. A., \& Kazis, L. E. (2009). Updated U.S. population standard for the veterans RAND 12-item health survey (VR-12). Quality of Life Research, 18(1), 43-52. https://doi.org/10.1007/ s11136-008-9418-2.

Senkowski, D., \& Heinz, A. (2016). Chronic pain and distorted body image: Implications for multisensory feedback interventions. Neuroscience \& Biobehavioral Reviews, 69, 252-259. https://doi. org/10.1016/j.neubiorev.2016.08.009.

Sheng, J., Liu, S., Wang, Y., Cui, R., \& Zhang, X. (2017). The link between depression and chronic pain: Neural mechanisms in the brain. Neural Plasticity, 2017, 9724371. https://doi.org/10.1155/ 2017/9724371.

Shokouhi, M., Clarke, C., Morley-Forster, P., Moulin, D. E., Davis, K. D., \& St Lawrence, K. (2017). Structural and functional brain changes at early and late stages of complex regional pain syndrome. The Journal of Pain. https://doi.org/10.1016/j.jpain.2017.09.007.

Sohn, H. S., Lee, D. H., Lee, K. J., Noh, E. C., Choi, S. H., Jang, J. H., Kim, Y. C., et al. (2016). Impaired empathic abilities among patients with complex regional pain syndrome (type I). Psychiatry Investigation, 13(1), 34-42. https://doi.org/10.4306/pi.2016.13.1. 34.

Spinhoven, P., Penninx, B. W., Hickendorff, M., van Hemert, A. M., Bernstein, D. P., \& Elzinga, B. M. (2014). Childhood trauma questionnaire: factor structure, measurement invariance, and validity across emotional disorders. Psychological Assessment, 26(3), 717729. https://doi.org/10.1037/pas0000002.

Taylor, M. F., \& Pooley, J. A. (2017). Sarcoma survivors' perspectives on their body image and functional quality of life post-resection/limb salvage surgery. European Journal of Cancer Care (English Language Edition), 26(6). https://doi.org/10.1111/ecc.12667.

Trojan, J., Speck, V., Kleinbohl, D., Benrath, J., Flor, H., \& Maihofner, C. (2019). Altered tactile localization and spatiotemporal integration in complex regional pain syndrome patients. European Journal of Pain (London, England), 23(3), 472-482. https://doi.org/10.1002/ejp. 1321

Turk, D. C., Dworkin, R. H., Revicki, D., Harding, G., Burke, L. B., Cella, D., Cleeland, C. S., Cowan, P., Farrar, J. T., Hertz, S., Max, M. B., \& Rappaport, B. A. (2008). Identifying important outcome domains for chronic pain clinical trials: an IMMPACT survey of people with pain. Pain, 137(2), 276-285. https://doi.org/10.1016/j. pain.2007.09.002.

Van Niel, C., Pachter, L. M., Wade Jr., R., Felitti, V. J., \& Stein, M. T. (2014). Adverse events in children: Predictors of adult physical and mental conditions. Journal of Developmental and Behavioral Pediatrics, 35(8), 549-551. https://doi.org/10.1097/dbp. 0000000000000102 .

Ware Jr., J., Kosinski, M., \& Keller, S. D. (1996). A 12-item short-form health survey: construction of scales and preliminary tests of reliability and validity. Medical Care, 34(3), 220-233.

Wilson, K. G., Eriksson, M. Y., D'Eon, J. L., Mikail, S. F., \& Emery, P. C. (2002). Major depression and insomnia in chronic pain. Clinical Journal of Pain, 18(2), 77-83. 
Wittkopf, P. G., Lloyd, D. M., \& Johnson, M. I. (2018). The effect of visual feedback of body parts on pain perception: A systematic review of clinical and experimental studies. European Journal of Pain (London, England), 22(4), 647-662. https://doi.org/10.1002/ ejp.1162.
Yaribeygi, H., Panahi, Y., Sahraei, H., Johnston, T. P., \& Sahebkar, A. (2017). The impact of stress on body function: A review. Excli J, 16, 1057-1072. https://doi.org/10.17179/excli2017-480.

Publisher's note Springer Nature remains neutral with regard to jurisdictional claims in published maps and institutional affiliations. 